\title{
Assessment of the Biological Damage in Whiplash Syndrome: Role of Digital Infrared Thermal Imaging (DITI) and Ultrasonography (US)
}

\author{
Gian Carlo Parenti ${ }^{1}$, Enzo Gualtieri ${ }^{2}$, Francesco Fontana ${ }^{2}$, Aleardo Benelli ${ }^{2}$, Fabrizio Albarello ${ }^{3}$ \\ ${ }^{1}$ Department of Radiology, OC’S.Maria delle Croci”, Ravenna, Italy \\ ${ }^{2}$ Department of Radiology, S.Anna Hospital, University of Ferrara, Ferrara, Italy \\ ${ }^{3}$ Health Center Medicina-Ravenna and Kura-Cesena, Cesena, Italy \\ Email: fabrizioalbarello@yahoo.it
}

Received October 31, 2013; revised November 30, 2013; accepted December 7, 2013

Copyright (c) 2013 Gian Carlo Parenti et al. This is an open access article distributed under the Creative Commons Attribution License, which permits unrestricted use, distribution, and reproduction in any medium, provided the original work is properly cited. In accordance of the Creative Commons Attribution License all Copyrights @ 2013 are reserved for SCIRP and the owner of the intellectual property Gian Carlo Parenti et al. All Copyright (c) 2013 are guarded by law and by SCIRP as a guardian.

\begin{abstract}
Objectives: To compare DITI vs US in a cohort of patients with whiplash syndrome for assessing soft tissues injuries of the cervical and dorsal spine. Methods: 70 patients presenting to clinic with traumatic cervical and/or dorsal spine injury and with a clinical diagnosis of whiplash syndrome underwent both DITI (AVIO TVS 2000) and US (GE Logic 5) of the following muscles: sternocleidomastoid, splenius, trapezius, longus colli and paravertebral muscles. DITI considered positive in the region with the most altered temperature among the injured area examinated (normal range $0^{\circ} \mathrm{C}$ $0.8^{\circ} \mathrm{C}$ ). US valued the cervical and dorsal region with a comparative examination of the soft tissues. The images taken with DITI were compared with the clinical and the sonographic outcomes respectively. US and DITI were considered a) congruent whether both had a positive outcome for the same muscle clinically injured; b) not congruent whether one of the two instruments had a different outcome then the clinical evidence. Wilcoxon paired test was used for statistical analysis. Results: DITI and US matched 153 of 233 (65\%) injured muscles. The association between DITI and US in the evaluation of the injured muscles was statistically significant for the following muscles: left trapezius $(\mathrm{p}<0.01)$, right trapezius $(\mathrm{p}<0.001)$ and right splenius $(\mathrm{p}<0.025)$. Conclusions: According to our preliminary study, DITI and US were both helpful for assessing soft tissues injuries in patients with whiplash syndrome, defining the extent of the biologic damage for a correct clinical-therapeutical management.
\end{abstract}

Keywords: Whiplash Syndrome; Digital Infrared Termography Imaging; Ultrasongraphy; Legal Medicine

\section{Introduction}

Whiplash syndrome is diagnosed on the basis of the nature of the trauma and of the patient's symptoms resulting from mechanical and tissue damage of the cervical and dorsal spine. These symptoms include: neck pain or stiffness; arm and hand numbness or pins and needles; disturbed jaw behaviour; difficulty swallowing; headache; vertigo; blurred vision; diminished hearing; lack of concentration; memory loss and psychological distress [1-3]. Digital Infrared Thermal Imaging (DITI) helps to rule out fractures and dislocations of the bony vertebrae and severe damage to spinal ligaments and discs. However, there are neither specific tests nor neuropsychological and electrophysiological studies for the diagnosis of whiplash syndrome [4].

The medical and legal implications of whiplash syndrome have led to the evaluation of alternative diagnostic techniques such as DITI in addition to traditional imaging techniques and modalities for assessing neck and spinal injuries [5-25]. This article presents the results of our research aimed at investigating soft tissue damage in a cohort of whiplash patients through the use of DITI and US.

\section{Materials and Methods}

This study was approved by the local institutional review board. Written informed consent was obtained from all patients before inclusion. The cohort comprised of 170 
patients (100 females and 70 males) aged 18 to 64 (average \pm SD: $42.7 \pm 12.1$ years) who experienced neck and back pain and had been clinically diagnosed as suffering from whiplash. The time frame was April 2012 to January 2013. The causes for the injury were the following:

- Car accident (140)

- Accidental fall (26)

- Bike accident (4)

All patients underwent DITI in the first instance, followed by a US investigation of the cervical and dorsal soft tissues in the region where the trauma had occurred. The DITI outcome was compared to:

The US results

The clinical results obtained through patient reports of where they had been injured and were experiencing the most severe pain.

The following muscles were analyzed with both methods, right hand side first: SCM muscles, trapezius muscle, splenius muscle, neck long muscles, paravertebral muscles.

The average interval between the trauma and the DITI was 20 days. The average interval between the trauma and the US was 24 days. The average interval between DITI and US was 2 days.

In order to assess the presence and establish the extent of soft tissue damage in patients with whiplash syndrome the following criteria were adopted:

- In the DITI investigation, evidence of an area in the cervical or dorsal region where the temperature was $0.8^{\circ} \mathrm{C}$ higher or lower than that in the surrounding areas.

- In the US investigation, presence of a thickened muscular tissue, an ill-defined myofibrillar mass and/or interrupted by hypoechoic areas.

- The presence of a hypoechoic area of fluid above or underneath muscular tissue due to intra or perimuscolar connective tissue hematoma.

- The radiography of the cervical spine didn't show signs of fractures or dislocations

- No clinical evidence of peripheral neurological damage.

\subsection{DITI Procedure}

DITI was carried out by AG or FF (with respectively 10 and 13 years' experience in the field).

The infrared thermographic inspection electrical system employed was an Avio TVS-2000 MkII ST (Tokyo, Japan) [17]. This instrument measures temperatures ranging from $10^{\circ} \mathrm{C}$ to $40^{\circ} \mathrm{C}$ with a 0.01 accuracy. Room temperature and humidity were controlled through an airrecycling system. The exposure to intense heat from the sun or electrical sources was kept to an absolute mini- mum. Patients were asked to abstain from physical activities in the 20 minutes preceding the DITI in order to lower body metabolism and allow temperature to settle [18]. During the investigation, patients wore no clothes in the upper part of the body and stood with their arms hanging down their sides. The quality of the digital images obtained was later digitally improved in order to increase spatial resolution. The three points presenting the highest difference in temperature were selected by an experienced doctor using a Celsius scale and a chromatic map. Each selected point was compared to either its symmetrical point located in the same position on the opposite side or to a point situated in a different location but having the same temperature and colour. Dedicated software calculated the temperature difference $\left(\Delta \mathrm{T}^{\circ}\right)$. Any difference in temperature included in the $0^{\circ} \mathrm{C}$ and $0.8^{\circ} \mathrm{C}$ bracket was considered normal.

\subsection{US Procedure}

A blind US investigation was performed by GCP, an operator with 15 years' experience in the field using a GE LOGIQ 5 Expert Ultrasound with a 7 - $14 \mathrm{MHz}$ high resolution linear probe. A musculoskeletal preset was used. In order to gain maximum resolution, focal depth and frame rate were adjusted manually.

\subsection{Comparison of DITI and US Outcome}

Data relating to the patient's age, clinical objectivity following the accident and possible causes for the whiplash syndrome were collected. During the DITI investigation, additional information on the location of the biological damage, the mechanism of the trauma and any posttraumatic therapy were noted. The DITI and US procedures were considered:

a) Congruent: when the location of the damage indicated by the patient coincided with the outcome of both procedures

b) Not congruent: when the location of the damage indicated by the patient did not coincide with the outcome of one of the procedures.

Furthermore, individual samples were compared when:

c) The ultrasound images indicated a thickened and hypoechoic muscular tissue with a low myofibrillar definition compatible with a post-traumatic oedema and the DITI revealed cool areas of hypothermia in the same region.

d) The ultrasound images demonstrated fluid collection containing low level echoes in the damaged region compatible with a post-traumatic oedema and the DITI revealed cool areas of hypothermia in the same region. 


\subsection{Statistical Analysis}

Using the Statistical Package for the Social Sciences (SPSS) version 20.0, IBM Corp, Armonk, NY, USA, the following were calculated:

- Average patient age.

- The average intervals between the occurrence of the trauma and the DITI procedure.

- The average intervals between the occurrence of the trauma and the US procedure.

- The interval between the DITI and the US investigations.

- The percentage of cases where the outcomes of the clinical diagnosis, DITI and US were congruent.

- The percentage of cases where the DITI and US investigations revealed the same type of damage.

The Wilcoxon paired test was employed to compare the outcomes of the DITI and US investigations on individual damaged muscles. A value of $\mathrm{p}<0.05$ was considered as statistically relevant.

Contingency Tables 1 and 2 were used for the comparison of the outcomes of both tests with clinical data. Both congruent and non-congruent results are reported.

\section{Results}

There were 170 patients taking part to this study, 100 females and 70 males with an average age of 42.6 years (range 18 - 67). 233 clinically diagnosed injured muscles were examined. Of these, 14 were splenius muscles ( 6 on the right and 8 on the left side), 195 trapezius muscles (101 on the right and 94 on the left side), 5 paravertebral muscles ( 4 on the right and 1 on the left), 14 neck long muscles (8 right, 6 left), 5 SCM muscles (4 right and 1 left).

The average interval between trauma and DITI, trauma and US and DITI and US was 32 days (range 0 - 153), 37 (range 1 - 174) and 4 (range 0 - 55) respectively.

The outcome for DITI and US investigations was positive for 154 damaged muscles out of 233, with a congruence rate of $66.1 \%$, and negative for 79 , with a non congruence rate of 33.9\% (Tables 1 and 2). 152 out of the 153 muscles positive to DITI, US and clinical examinations shared the characteristics mentioned above in points (c) e (d).

Statistical data reported as congruent the outcomes of DITI and US in assessing biological damage in the following muscles:

- left trapezius $(\mathrm{p}<0.01)$

- right trapezius $(\mathrm{p}<0.001)$

- right splenius $(\mathrm{p}<0.025)$

\section{Discussion}

The term 'whiplash syndrome' is commonly used to refer to various symptoms developed as a result of damage to cervical and dorsal soft tissue as a result of a trauma. Cailliet [2] reports that the term was coined by Dr. Harold Crowe (1928), who noted that acceleration-deceleration resulting from an external impact, had a 'lash-like effect' in the neck and upper body. Post-traumatic cervical syndrome is the third most common type of injury in car accidents, after head and leg injuries. Its occurrence in Western countries has been estimated at around $1 / 1000$ a year [1,3-5].

In 1995 the Québec Task Force (QTF) divided whiplash-associated disorders into four grades [26]:

- Grade 1: complaints of pain, stiffness or tenderness in the neck but no physical signs noted by the doctor.

- Grade 2: neck complaints and the examining doctor finds a decreased range of motion and point tenderness in the neck.

- Grade 3: neck complaints plus neurological signs such as decreased deep tendon reflexes, weakness and sensory deficits.

- Grade 4: neck complaints and fracture or dislocation, or injury to the spinal cord.

This classification is not universally recognized as a viable clinical tool in the assessment of whiplash syndrome. Whiplash neck pain is difficult to investigate with imaging techniques, particularly when the extent of the damage is slight. Other types of investigations are needed in order to rule out any post-traumatic lesions. X-rays to the cervical and dorsal region can document fractures, displacements and unnatural reduction of the lordotic curvature as a consequence of 'stretch reflex' when neck muscles tighten to protect the neck and spinal cord from fractures that could be caused by excessive motion. Electromyography of the upper limbs can reveal signs of suffering in one or more nervous roots of the brachial plexus.

Medical literature points out the important role of US in documenting a trauma to the muscles and tendons $[5,6]$. However, the cervical region is often difficult to investigate. Documenting any muscular alteration in a region with complex fascial layers is time consuming and expensive. It is common knowledge how traumas trigger in the body an innate inflammatory response. DITI is particular effective in locating areas where the temperature has been altered as a result of post-traumatic oedema [7]. Our experience has shown that DITI can help to find the damaged area with a high degree of precision, especially when it affects the trapezius and splenius muscles. A DITI outcome revealing the presence of hypothermic areas can subsequently be validated by a US presenting hypoechoic alterations of the intra and perimuscular and subcutaneous tissue in the same areas.

In our study, the US investigation in the areas that appeared hypertermic in the DITI investigation showed the presence of a thickened muscle belly and a hypoechoic 
Table 1. Contingency tables of DITI and US outcomes for the following muscles examinated: splenius muscle (a); trapezius muscle (b); neck long muscles (c); paravertebral muscles (d); SCM muscles (e). The number of cases negative, with oedema and with hematoma at US scan and the number of cases negative, with hyperthermia and with hypothermia at DITI are reported.

(a)

\begin{tabular}{|c|c|c|c|c|c|}
\hline & \multirow{2}{*}{ RIGHT } & \multicolumn{3}{|c|}{ DITI } & \multirow{2}{*}{ Total } \\
\hline & & negative & hyperthermia & hypothermia & \\
\hline \multirow{4}{*}{ US } & negative & 164 & 5 & 0 & 169 \\
\hline & oedema & 0 & 1 & 0 & 1 \\
\hline & hematoma & 0 & 0 & 0 & 0 \\
\hline & Total & 164 & 6 & 0 & 170 \\
\hline \multirow{6}{*}{ US } & \multirow{2}{*}{ LEFT } & \multicolumn{3}{|c|}{ DITI } & \multirow{2}{*}{ Total } \\
\hline & & negative & hyperthermia & hypothermia & \\
\hline & negative & 162 & 4 & 0 & 166 \\
\hline & oedema & 2 & 1 & 0 & 3 \\
\hline & hematoma & 0 & 0 & 1 & 1 \\
\hline & Total & 164 & 5 & 1 & 170 \\
\hline
\end{tabular}

a: US and DITI outcomes for splenius.

(b)

\begin{tabular}{|c|c|c|c|c|c|}
\hline & \multirow{2}{*}{ RIGHT } & \multicolumn{3}{|c|}{ DITI } & \multirow{2}{*}{ Total } \\
\hline & & negative & hyperthermia & hypothermia & \\
\hline \multirow{4}{*}{ US } & negative & 69 & 28 & 0 & 97 \\
\hline & oedema & 2 & 68 & 0 & 70 \\
\hline & hematoma & 1 & 0 & 2 & 3 \\
\hline & Total & 72 & 96 & 2 & 170 \\
\hline \multirow{6}{*}{ US } & \multirow{2}{*}{ LEFT } & \multicolumn{3}{|c|}{ DITI } & \multirow{2}{*}{ Total } \\
\hline & & negative & hyperthermia & hypothermia & \\
\hline & negative & 76 & 15 & 0 & 91 \\
\hline & oedema & 5 & 71 & 1 & 77 \\
\hline & hematoma & 0 & 0 & 2 & 2 \\
\hline & Total & 81 & 86 & 3 & 170 \\
\hline
\end{tabular}

b: US and DITI outcomes for trapezius.

(c)

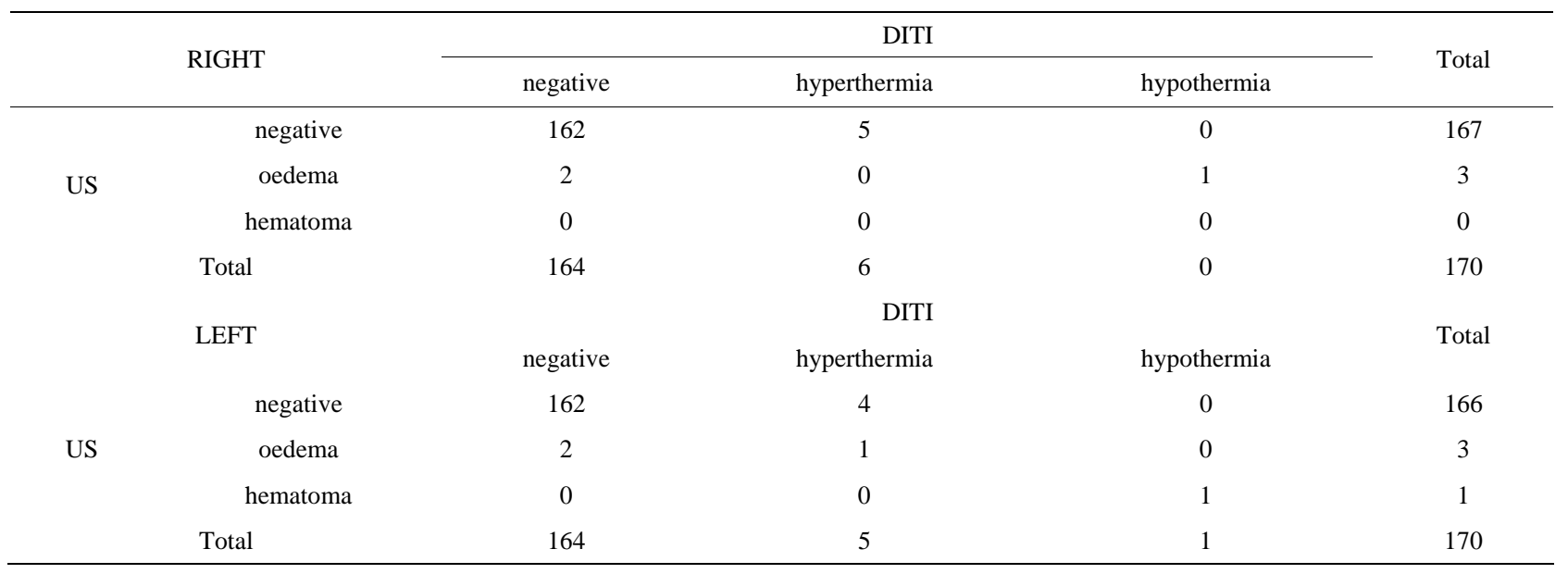

c: US and DITI outcomes for long neck muscles. 
(d)

\begin{tabular}{|c|c|c|c|c|c|}
\hline & \multirow{2}{*}{ RIGHT } & \multicolumn{3}{|c|}{ DITI } & \multirow{2}{*}{ Total } \\
\hline & & negative & hyperthermia & hypothermia & \\
\hline \multirow{4}{*}{ US } & negative & 166 & 2 & 0 & 168 \\
\hline & oedema & 1 & 1 & 0 & 2 \\
\hline & hematoma & 0 & 0 & 0 & 0 \\
\hline & Total & 167 & 3 & 0 & 170 \\
\hline \multicolumn{5}{|c|}{ DITI } & \multirow[b]{2}{*}{ Total } \\
\hline \multirow{5}{*}{ US } & LEFT & negative & hyperthermia & hypothermia & \\
\hline & negative & 169 & 0 & 0 & 169 \\
\hline & oedema & 1 & 0 & 0 & 1 \\
\hline & hematoma & 0 & 0 & 0 & 0 \\
\hline & Total & 170 & 0 & 0 & 170 \\
\hline
\end{tabular}

d: US and DITI outcomes for paravertebral muscles.

(e)

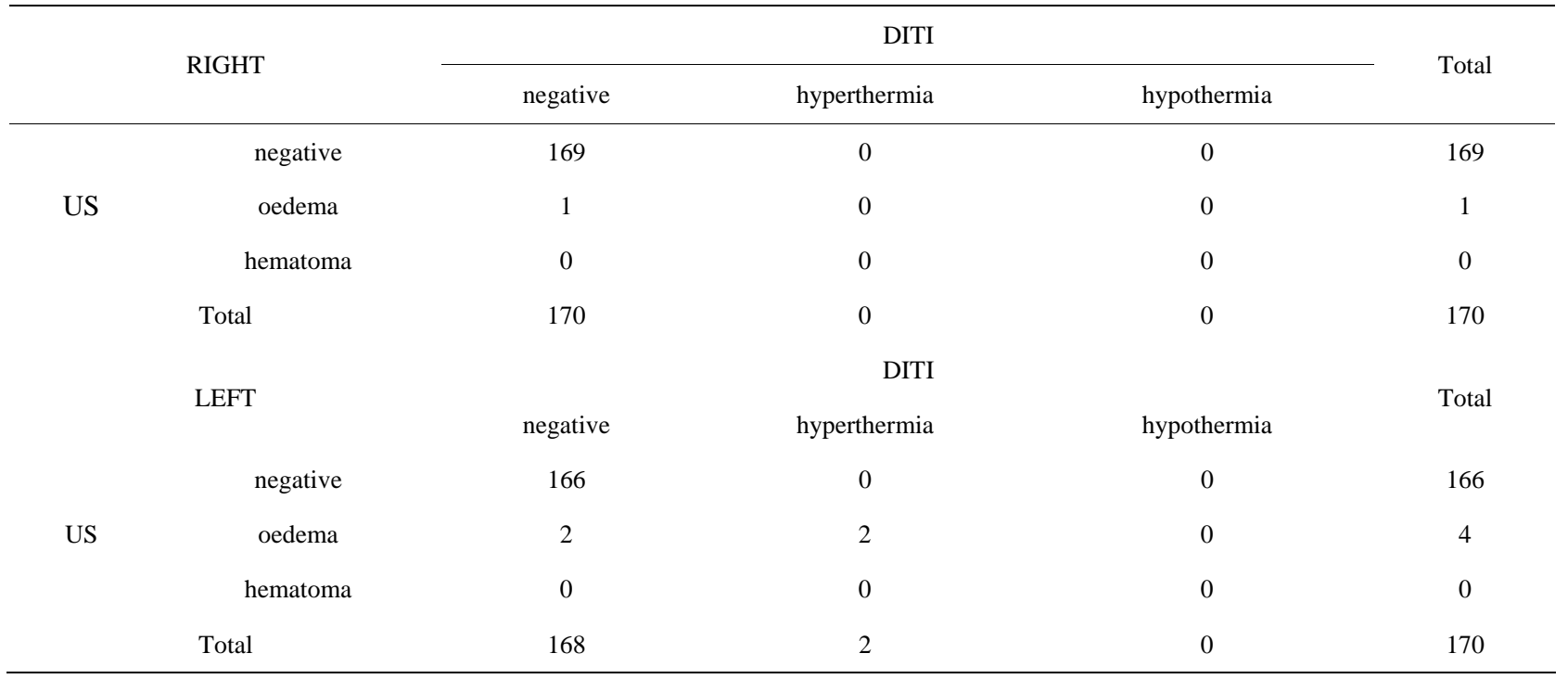

e: US and DITI outcomes for SMC.

myofibrils structure of the muscle (Figure 1). The US scan to the hypotermic regions showed hypo echoic areas suggesting the presence of haematoma or liquid in the peri-and interfasciae due to direct or contusive trauma (Figure 2). In 4 of the patients, the DITI investigation revealed a thin and narrow cooler area in the cervical region that was negative to the US; with the help of clinical objectivity we interpreted these results as evidence of an enflamed root of the spinal nerve (Figure 3). In 6 of the patients where DITI and US outcomes were not congruent, the thermal alterations were at the limit of the temperature bracket $\left(0.8^{\circ} \mathrm{C}\right)$; while the ultrasound identified only small shadowy areas. In 8 of the patients the interval between DITI and US was longer than 60 days: the disparity between the DITI and US outcomes could therefore be explained as the consequence of an improvement due to the intervening therapeutic treatment. The investigation of 10 of the patients who had negative DITI and US outcomes was congruent with the presence of scarce symptoms and the fact that the trauma had occurred over 90 days earlier (Figure 4). We believe that DITI can help to determine the region with the highest thermal variation and allow subsequent investigations to concentrate on that region. A similar approach is mentioned in medical literature with reference to a group of young disabled patients who had suffered a trauma. Only the young patients who had tested positive to DITI were subsequently given $\mathrm{X}$-rays, thus avoiding an indiscrimi- 
Table 2. congruence and non congruence rate between patient report, DITI and US outcome in the muscles injured.

\begin{tabular}{ccc}
\hline Muscles & Congruence & Non congruence \\
\hline Splenius R & 1 & 5 \\
Splenius L & 2 & 6 \\
Trapezius R & 71 & 30 \\
Trapezius L & 74 & 20 \\
Paravertebral R & 1 & 3 \\
Paravertebral L & 0 & 1 \\
Neck long R & 1 & 7 \\
Neck long L & 2 & 4 \\
SCM R & 0 & 1 \\
SCM L & 2 & 2 \\
Total & 154 & 79 \\
\% of Total & $66.1 \%$ & $33.9 \%$ \\
\hline
\end{tabular}

nate exposure to radiation [8].

Although this is a pilot study based on a limited sample of patients, it leads us to believe that non congruence between DITI and US occurs when there is a prolonged time lapse between the occurrence of the trauma and the investigations and any possible medical or physiological therapy conducted in the intervening period and/or the presence of small thermal variations that cannot be picked up by ultrasound. As insurance companies are requiring more detailed proof of injury in whiplash syndrome claims, especially in instances where the damage is slight, DITI and US can be suitable instruments in determining the location and the extent of the biological damage.

The Gazzetta Ufficiale della Repubblica Italiana n. 71 on March 2012, S.O. n. 53, published the 24th March 2012 n. 27 Law, which modified the previous 24 January by-law 2012, n.1 [27], which ruled on 'competition, infrastructures development and competitivity' and ruled that whiplash associated disorders (WAD) following a “Cervical Acceleration-Deceleration” (CAD) should receive no compensation unless they can proved with an

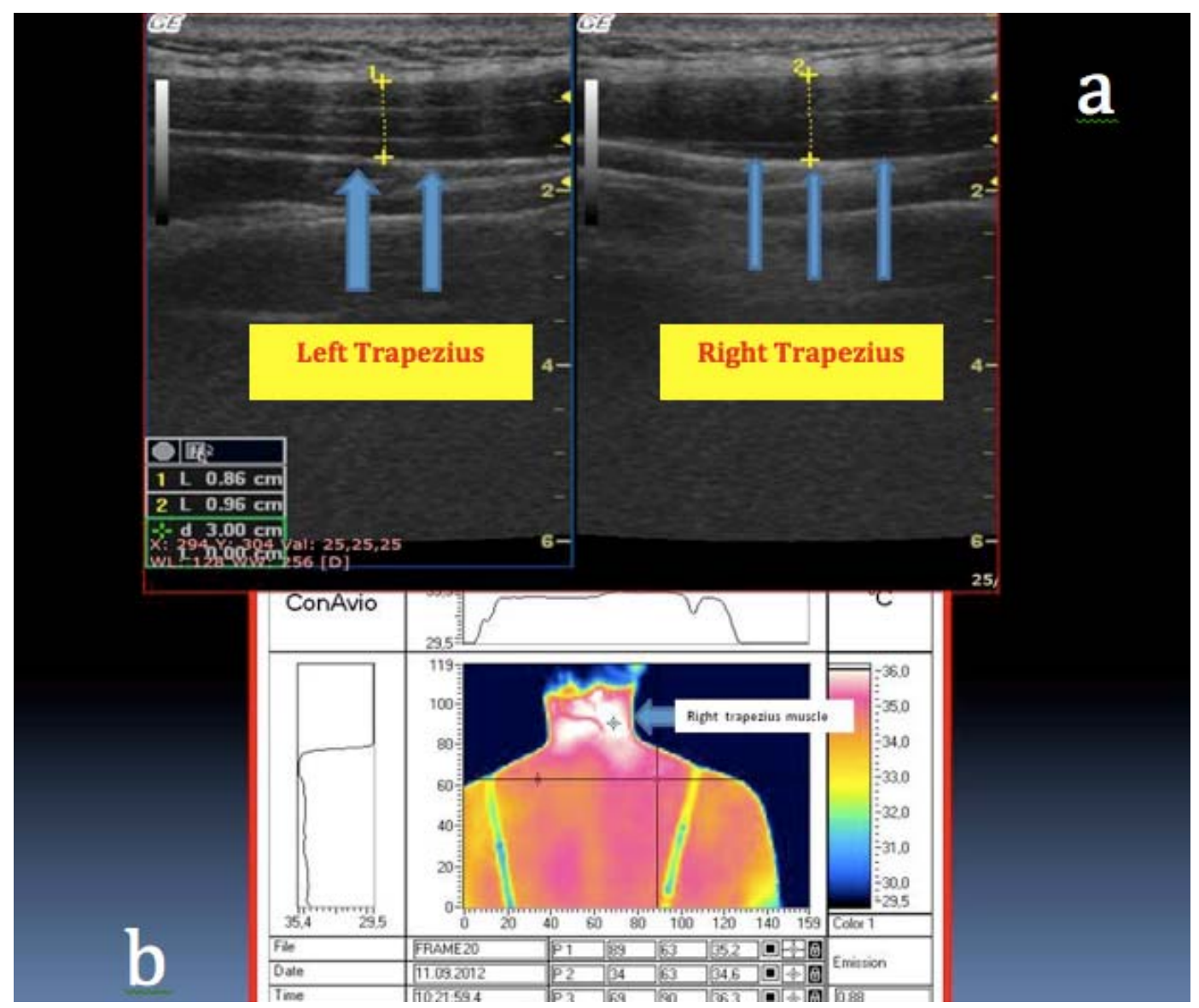

Figure 1. (a) US: evidence of post-traumatic oedema in the right trapezius which appears thickened, hypoechoic and with low defined myofibrillar structure, compared with the controlateral one; (b) DITI: evidence of a hyperthermic area in the upper right trapezius. 


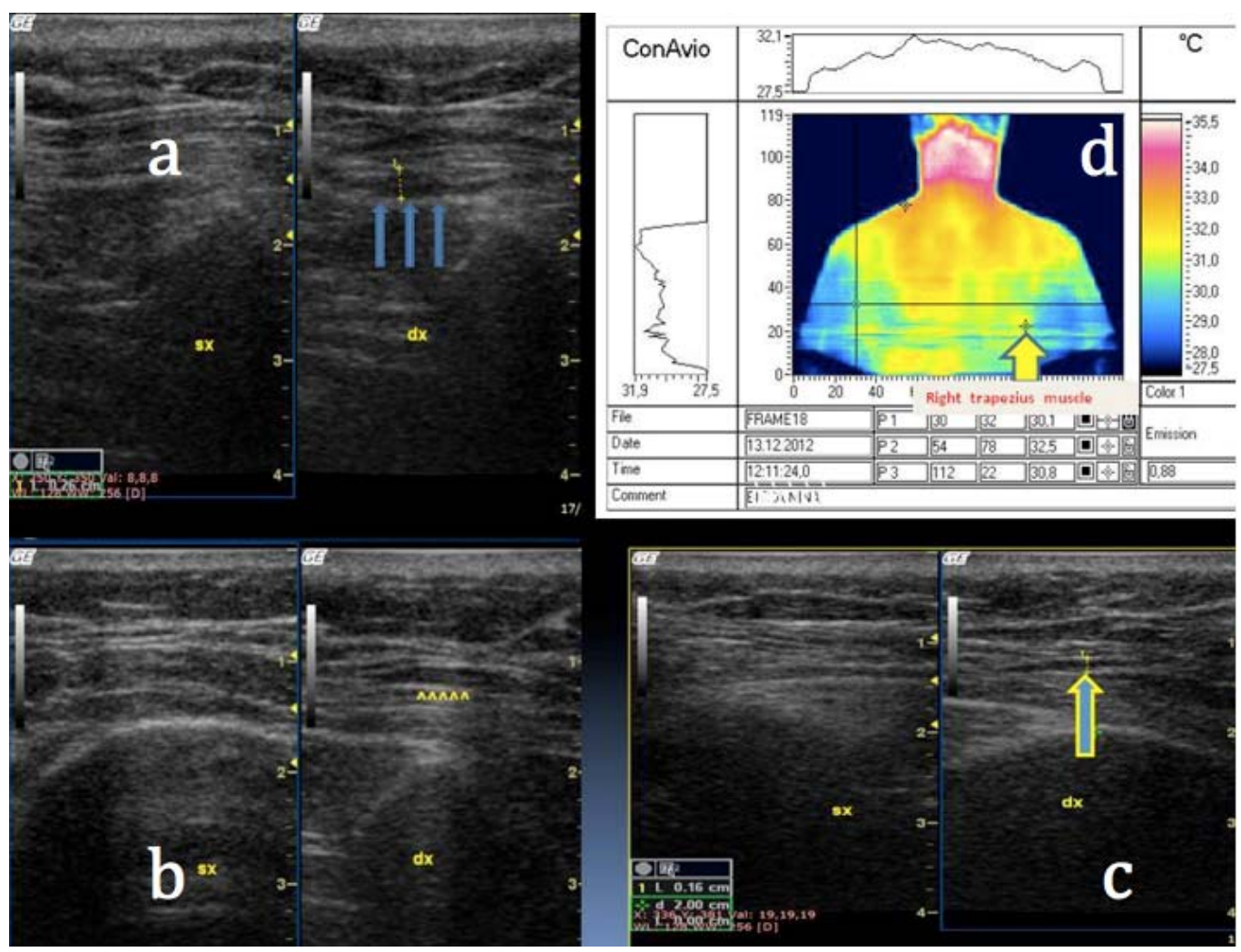

Figure 2. (a)-(c) US: hypoechoic area of fluid collection in the perimuscolar connective tissue associated with hematoma within the fascia of the right trapezius; (d) DITI: hypothermic area in the right trapezius.

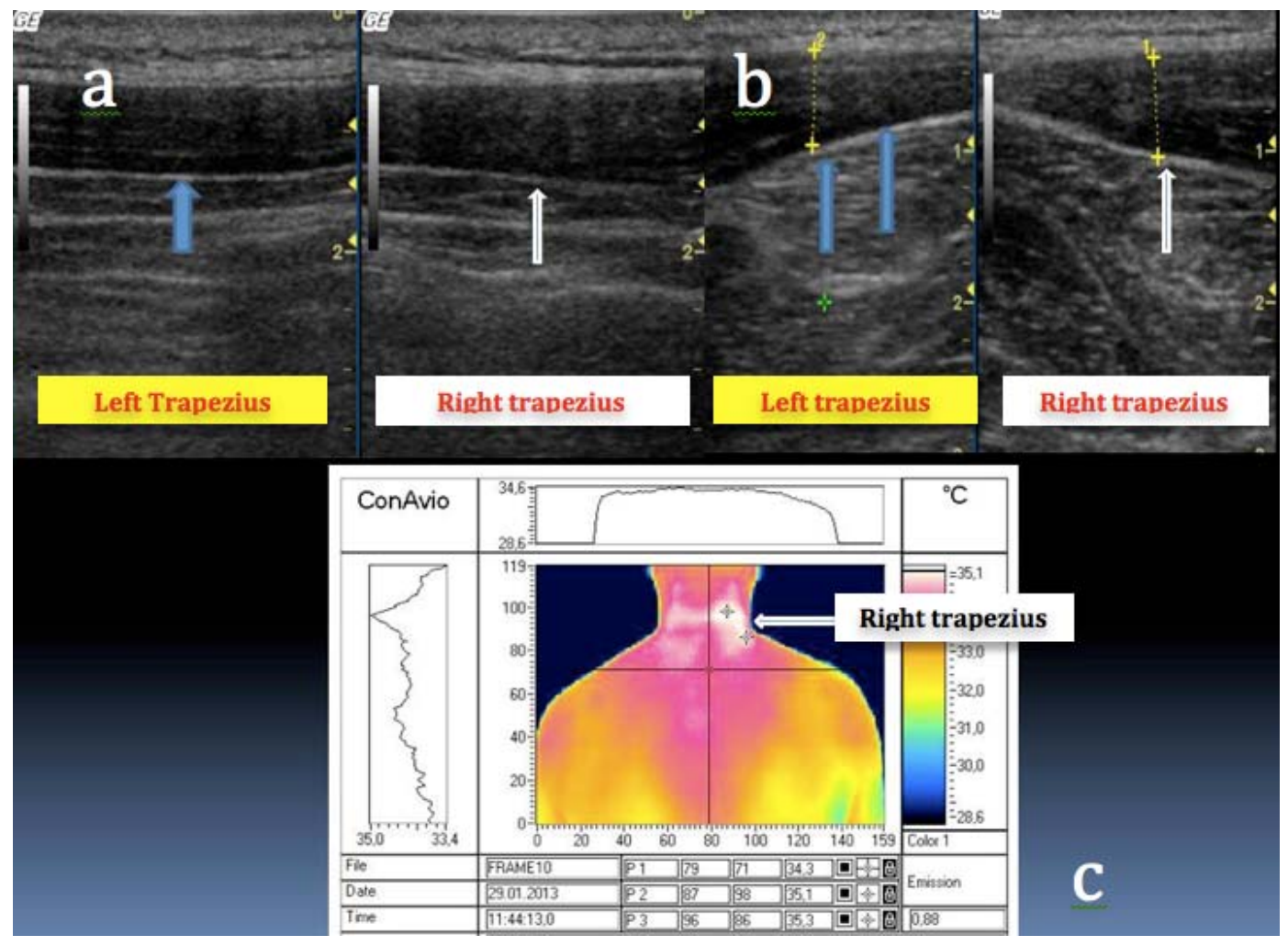

Figure 3. (a), (b) US: negative outcome: no significative echogenic pattern within the soft tissue of the cervical region; (c) DITI: hyperthermic stripe-like area in the right cervical area compatible with post-traumatic radiculitis. 


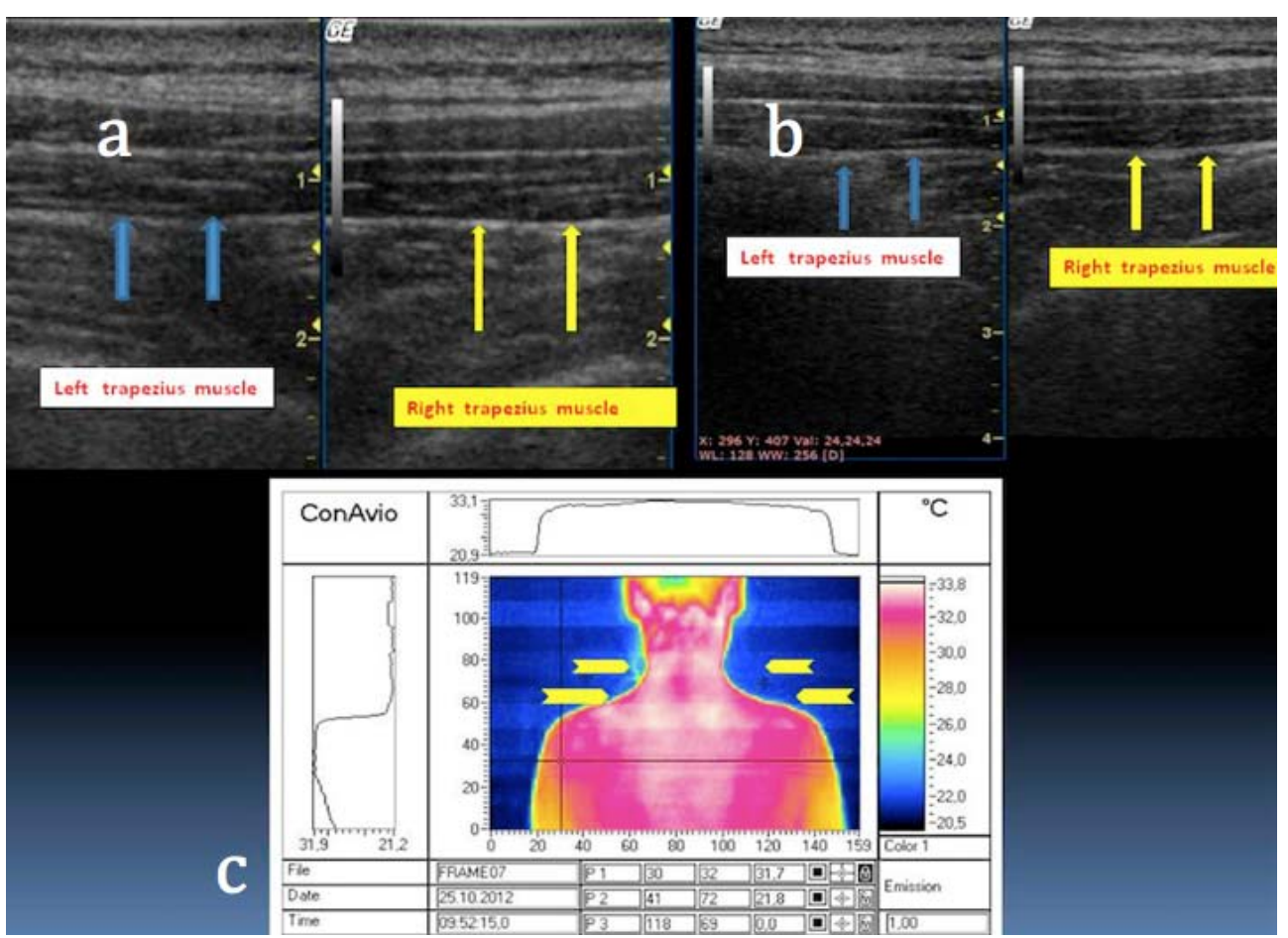

Figure 4. (a), (b) US: negative outcome of the cervical region; (c) DITI: hyperthermic dots with temperature variations of no significance $\left(<0-0.80^{\circ} \mathrm{C}\right)$.

objective instrumental assessment. This change in the law gives a further incentive to look for new ways of assessing and documenting biological damage in whiplash patients. Our limited experience has shown DITI and US to be useful and effective, non-invasive alternatives to traditional imaging techniques in documenting biological damage to cervical and dorsal soft tissue.

\section{Conclusion}

Our preliminary study has highlighted how DITI and US can be helpful in evaluating and documenting whiplash injuries, particularly in cases when the outcome of radiology procedures has been negative. DITI and US have proven to be effective alternative methods for providing detailed information on the location and extent of trauma suffered by whiplash patients. This is invaluable for both a correct assessment and adequate treatment of the injury from a legal perspective.

\section{REFERENCES}

[1] J. DeLany, “Acceleration-Deceleration Injuries: Whiplash Syndrome,” NMT Center and JudithDeLany, 1999.

[2] R. Cailliet, “Neck and Arm Pain,” FA Davis, Philadelphia, 1991.

[3] H. Crowe, "Injuries to the Cervical Spine," the Annual Meeting of the Western Orthopedic Association, San Francisco, 1928.
[4] A. A. Rodriquez, K. P. Barr and S. P. Burns, "Whiplash: Pathophysiology, Diagnosis, Treatment, and Prognosis," Muscle Nerve, Vol. 29, No. 6, 2004, pp. 768-781. http://dx.doi.org/10.1002/mus.20060

[5] A. De Marchi, T. Robba, E. Ferrarese and C. Faletti, "Imaging in Musculoskeletal Injuries: State of the Art," Radiologia Medica, Vol. 110, No. 6, 2005, pp. 115-131.

[6] J. L. Brasseur and M. Tardieu, "Ecografia Dell’Apparato Locomotore,” Verducci Editore, 2001, pp. 25-30.

[7] K. Bohndorf, H. Imhof and T. L. Pope, "Diagnostica per Immagini Muscolo Scheletrica,” Ed. Masson, 2003, pp. 30-35.

[8] M. Anbar, S. A. Brown, L. Milescu, J. A. Babalola and S. Buffalo, "Clinical Application of DAT Using a QWIP FPA Camera: (USA)," Proceedings of SPIE Infrared Technology and Applications, Vol. 3698, 1999, p. 93.

[9] S. Dragoni, A. Baragone, G. Colombo and T. Pamic, "Valutazione Dell'Efficacia di Nuove Bende Medicate Mediante L'impiego Della Teletermografia in Patologia Sportive,” La Riabilitazione, Vol. 23, No. 4, 1990.

[10] H. H. Al Nakhli, J. S. Petrofsky, M. S. Laymon and L. S. Berk, "The Use of Thermal Infra Red Imaging to Detect Delayed Onset Muscle Soreness,” Journal of Visualized Experiments, Vol. 59, 2012, p. 3551.

[11] HH. Al Nakhli, JS. Petrofsky, MS Laymon, D. Arai, K. Holland, LS. Berk, "The use of thermal infrared imaging to assess the efficacy of a therapeutic exercise program in individuals with diabetes," Diabetes Technology \& Therapeutics, Vol. 14, No. 2, 2012, pp. 159-167. http://dx.doi.org/10.1089/dia.2011.0187 
[12] C. T. Silva, N. Naveed, S. Bokhari, K. E. Baker, L. H. Staib, S. M. Ibrahim, K. Muchantef and T. R. Goodman, "Early Assessment of the Efficacy of Digital Infrared Thermal Imaging in Pediatric Trauma," Emergency Radiology, Vol. 19, No. 3, 2012, pp. 203-209. http://dx.doi.org/10.1007/s10140-012-1027-2

[13] D. Mikulska, "Contemporary Application of Infrared Imaging in Mediacal Diagnostics," Annales Academiae Medicae Stetinensis, Vol. 52, No. 1, 2006, pp. 35-39.

[14] C. L. Romanò, N. Logoluso, F. Dell’oro, A. Elia and L. Drago, "Telethermographic Findings after Uncomplicated and Septic Total Knee Replacement,” The Knee, Vol. 19, No. 3, 2012, pp. 193-197.

[15] E. F. Ring and K. Ammer, "Infrared Thermal Imaging in Medicine,” Physiological Measurement, Vol. 33, 2012, pp. R33-46. http://dx.doi.org/10.1088/0967-3334/33/3/R33

[16] A. E. Denoble, N. Hall, C. F. Pieper and V. B. Kraus, "Patellar Skin Surface Temperature by Termography Reflects Knee Osteoarthritis Severity,” Clinical Medicine Insights: Arthritis and Musculoskeletal Disorders, Vol. 15, No. 3, 2010, pp. 69-75.

[17] S. C. Fok, E. Y.-K. Ng and K. Tai, "Early Detection and Visualization of Breast Tumor with Thermogram and Neural Network," Journal of Mechanics in Medicine and Biology, Vol. 2, 2002, pp. 185-196. http://dx.doi.org/10.1142/S0219519402000344

[18] E. Y. Ng, L. N. Ung, F. C. Ng and L. S. J. Sim, "Statistical Analysis of Healthy and Malignant Breast Thermography," International Journal of Medical Engineering \& Technology, Vol. 25, 2001, pp. 253-263.

[19] L. Barnsley, S. Lord and N. Bogduk, "Whiplash Injury," Pain, Vol. 58, No. 3, 1994, pp. 283-307.
[20] S. H. Norris and I. Watt, "The Prognosis of Neck Injuries Resulting from Rear-End Vehicle Collisions,” The Journal of Bone and Joint Surgery (British), Vol. 65, No. 5, 1983, pp. 608-611.

[21] C. Debilio, "La Sindrome Cervicale Post-Traumatica," 2013. http://www.reumatologiadebilio.de

[22] U. Bjornstig, C. Hildingsson and G. Toolanen, "SoftTissue Injury of the Neck in a Hospital Based Material," Scandinavian Journal of Social Medicine, Vol. 18, No. 4, 1990, pp. 263-267.

[23] P. Cote, J. D. Cassidy, L. Carroll, J. W. Frank and C. Bombardier, "A Systematic Review of the Prognosis of Acute Whiplash and a New Conceptual Framework to Synthesize the Literature,” Spine, Vol. 26, No. 9, 2001, pp. E445-458.

[24] J. Kivioja, I. Jensen and U. Lindgren, "Neither the WADClassification Nor the Quebec Task Force Follow-Up Regimen Seems to Be Important for the Outcome after a Whiplash Injury. A Prospective Study on 186 Consecutive Patients,” European Spine Journal, Vol. 17, No. 7, 2008, pp. 930-935. http://dx.doi.org/10.1007/s00586-008-0675-0

[25] A. Merla and G. L. Romani, "Functional infrared imaging in clinical applications,” In: J. D. Bronzino, Ed., The Biomedical Engineering Handbook, CRC Press, Boca Raton, 2005, pp. 32.1-32.13.

[26] Update Quebec Task Force Guidelines for the Management of Whiplash-Associated Disorders, 2001.

[27] La Gazzetta Ufficiale della Repubblica Italiana n.71 March 2012, S.O. n. 53, 24 March 2012, Law n. 27 